\title{
Assessment of the pharmaceutical quality of omeprazole capsule brands marketed in Egypt
}

A. El-Sayed, ${ }^{1}$ N.A. Boraie, ${ }^{1}$ F.A. Ismail, ${ }^{1}$ L.K. El-Khordagui ${ }^{1}$ and S.A. Khalil ${ }^{1}$

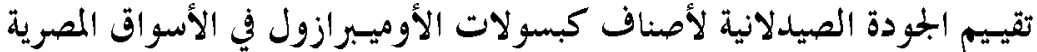

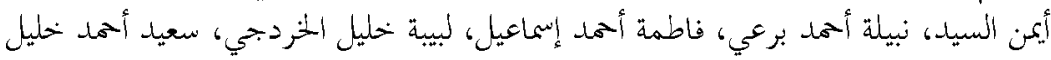

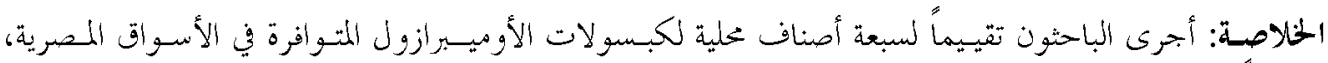

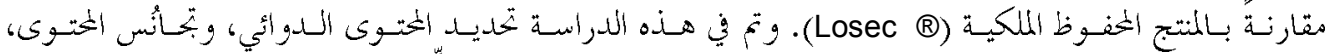

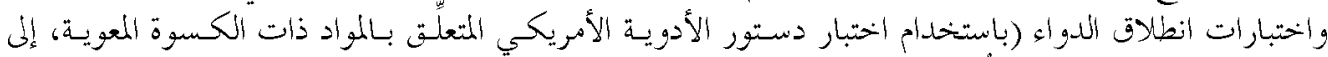

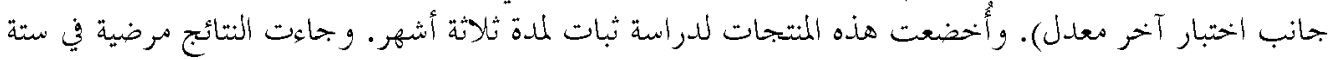

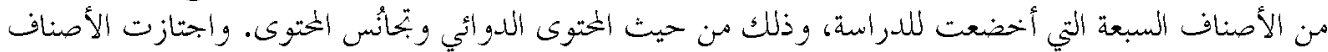

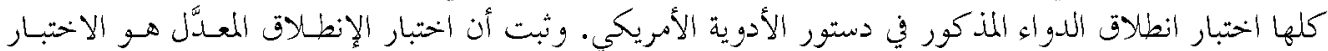

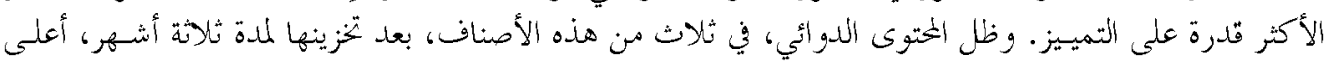

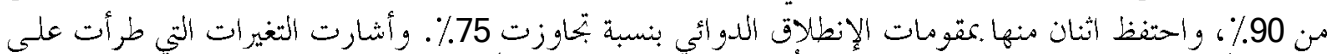

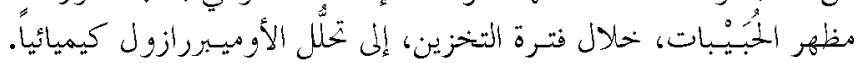

ABSTRACT The pharmaceutical quality of 7 local omeprazole capsule brands in Egypt was assessed relative to the proprietary product $\left(\operatorname{Losec}^{\circledR}\right)$. Drug content, content uniformity, drug release (using USP test for enteric coated articles and a modified release test) were determined. Products were subjected to a 3-month stability study. Of the 7 brands, 6 had satisfactory drug content and content uniformity. All brands passed the USP drug release test. The modified release test proved to be more discriminative. After 3 months storage, drug content of 3 brands remained $>90 \%$ and 2 of these brands maintained drug release above $75 \%$. Changes in pellet appearance during storage were indicative of omeprazole chemical degradation.

Évaluation de la qualité pharmaceutique des différentes spécialités d'oméprazole gélule commercialisées en Égypte

RÉSUMÉ La qualité pharmaceutique de 7 spécialités génériques d'oméprazole gélule fabriquées par des laboratoires égyptiens a été évaluée par comparaison avec la spécialité originale de référence $\left(\right.$ Losec $\left.^{\circledR}\right)$. Ont été déterminés le dosage du principe actif, l'uniformité de la composition et la libération du principe actif (via le test pour formulations à enrobage entérique de l'USP [Pharmacopée américaine] et un test pour formulations à libération modifiée). Les produits ont été soumis à un essai de stabilité de 3 mois. Le dosage du principe actif et l'uniformité de la composition se sont avérés satisfaisants pour 6 des 7 génériques étudiés. Tous les génériques ont passé avec succès le test de libération du principe actif de l'USP. Le test pour formulations à libération modifiée s'est révélé plus discriminant. Au bout de 3 mois de conservation, la teneur en principe actif de 3 génériques demeurait $>90 \%$ et pour deux d'entre eux la libération du principe actif était supérieure à $75 \%$. Les modifications de l'aspect des microgranules constatées pendant l'essai de stabilité étaient révélatrices de la dégradation chimique de l'oméprazole.

${ }^{1}$ Department of Pharmaceutics, Faculty of Pharmacy, University of Alexandria, Alexandria, Egypt (Correspondence to F.A. Ismail: fatmaismail@yahoo.com).

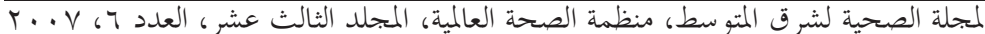




\section{Introduction}

Omeprazole, a proton pump inhibitor which has greater anti-secretory activity than $\mathrm{H}_{2}$ antagonists, has been widely used in the treatment of reflux oesophagitis, ZollingerEllison syndrome and peptic ulcer disease [1]. Being unstable in acidic $\mathrm{pH}$ [2], omeprazole is marketed as enteric-coated pellets encased in hard gelatin capsules. Pellets may undergo changes upon storage involving mainly enteric performance and release characteristics [3]. After encasing into capsules, additional storage-induced changes in the capsule shell may take place $[4,5]$. Thus, post-marketing follow-up is necessary to monitor probable changes which may affect the performance of omeprazole capsules.

Omeprazole is currently marketed in Egypt by a number of pharmaceutical companies using coated microgranules from different origins and using different types of packaging (Table 1). Differences in the quality of granules coating may be a source of variability in the in vitro and consequently in vivo availability of omeprazole [1]. Packaging types have been reported to be an additional factor significantly influencing formulae stability and performance [6]. Moreover, there are wide variations in price in the marketed omeprazole products, particularly between generic products and the proprietary one. The price per capsule ranges from Egyptian pounds (LE) 1.5 to 7 (US\$1 $=$ LE 6.8 at the time of the study) (Table 1). Recurring gastrointestinal tract (GIT) conditions necessitate long-term therapy with long-term cost implications. Remak et al. suggested an economic model to compare the cost and effectiveness of 7 proton pump inhibitors (PPIs) in patients suffering from gastro-oesophageal reflux disease (GERD) [7]. Accordingly, there appear to be many sources of variation in the pharmaceutical performance of omeprazole capsules.
The objective of the present study therefore was to assess the quality of different brands of omeprazole capsules available on the Egyptian market and the efficiency of the national regulatory system to ensure the pharmaceutical quality of multisource products or product components.

\section{Methods}

Omeprazole standard was obtained from Astra Hässle AB, Sweden. Seven commercial generic brands of omeprazole capsule products $(20 \mathrm{mg}$ ) marketed in Egypt (Table 1) were purchased from local pharmacies and compared to the original innovator product $\left(\operatorname{Losec}^{\circledR}\right)$ manufactured by Astra. Variations in manufacturing-expiry date ranges were small. Acetonitrile (Fisher Scientific, United Kingdom) and methanol (Riedel-de Häen, Germany) were of high performance liquid chromatography (HPLC) grade. Other chemicals were of analytical grade.

\section{Determination of omeprazole content}

The omeprazole content of the products was determined using the HPLC method reported by Storpirtis and Rodrigues [8] with slight modification. The HPLC system used (Perkin Elmer series 200, United States) was equipped with a pump, vacuum degasser, ultraviolet/visible detector, autosampler and a chromatography interface 600 series link operated by a software system version 6.2. A reserved phase column, Spheri-5, RP-18, 5, $220 \times 4.6 \mathrm{~mm}$ (Perkin Elmer, Brownlee columns) was used. The mobile phase consisted of $40 \%(\mathrm{v} / \mathrm{v})$ acetonitrile and $60 \%(\mathrm{v} / \mathrm{v})$ phosphate buffer solution $\mathrm{pH} 7.6$ flowing at a rate of $1 \mathrm{~mL} /$ minute; the detection wavelength was $302 \mathrm{~nm}$. Analysis was performed at room temperature with an injection volume of $20 \mu \mathrm{L}$. 


\begin{tabular}{|c|c|c|}
\hline $\begin{array}{l}\text { Product } \\
\text { code }\end{array}$ & $\begin{array}{c}\text { Price/ } \\
\text { capsule (LE) }\end{array}$ & Packaging \\
\hline Innovator & 7 & $\begin{array}{l}\text { White high-density polyethylene plastic } \\
\text { bottle with screw security plastic cap } \\
\text { and containing a desiccant disc }\end{array}$ \\
\hline Brand A & 1.5 & $\begin{array}{l}\text { White high-density polyethylene plastic } \\
\text { bottle with screw security plastic cap } \\
\text { and containing a desiccant disc }\end{array}$ \\
\hline Brand B & 3 & $\begin{array}{l}\text { PVC/PVdC-aluminium blister; each } \\
\text { blister contains } 5 \text { capsules }\end{array}$ \\
\hline Brand C & 3.14 & $\begin{array}{l}\text { Amber glass bottle containing a } \\
\text { desiccant disc and having screw } \\
\text { aluminium cap }\end{array}$ \\
\hline Brand D & 2.36 & $\begin{array}{l}\text { Amber glass bottle containing a } \\
\text { desiccant disc and having screw } \\
\text { aluminium closure }\end{array}$ \\
\hline Brand $E 1^{d}$ & 3 & $\begin{array}{l}\text { Laminated aluminium-aluminium } \\
\text { strip. Each strip contains } 4 \text { capsules }\end{array}$ \\
\hline Brand E2 ${ }^{\mathrm{d}}$ & 3.03 & $\begin{array}{l}\text { Amber glass bottle containing a } \\
\text { desiccant disc and having screw } \\
\text { aluminium closure }\end{array}$ \\
\hline Brand F & 3.03 & $\begin{array}{l}\text { White high-density polyethylene } \\
\text { plastic bottle containing a desiccant } \\
\text { disc and having screw security plastic } \\
\text { cap. The whole bottle is wrapped in a } \\
\text { clear plastic second wrapping that is } \\
\text { removed during opening of the bottle. }\end{array}$ \\
\hline \multicolumn{3}{|c|}{ 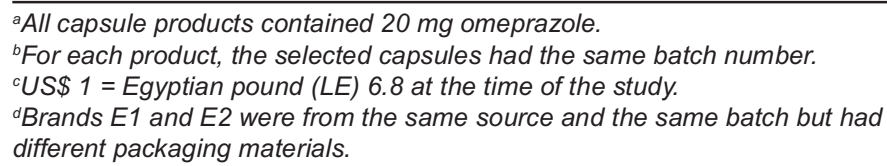 } \\
\hline
\end{tabular}

An amount of the pellets equivalent to 20 $\mathrm{mg}$ of omeprazole was accurately weighted and sonicated with $60 \mathrm{~mL}$ of $0.1 \mathrm{~N} \mathrm{NaOH}$ (ultrasonic bath) for 10 minutes. Methanol $(20 \mathrm{~mL})$ was added and the mixture sonicated for 5 minutes. The volume was completed with $0.1 \mathrm{~N} \mathrm{NaOH}$ to $100 \mathrm{~mL}$, and the mixture filtered through a Millipore nylon filter $(0.45 \mu \mathrm{m} \times 25 \mathrm{~mm})$. The filtrate was kept in the refrigerator protected from light; under these conditions it is expected to be stable for 3 days [8]. Before analysis, the filtrate was diluted with water/acetonitrile mixture $(60: 40)$ to a final concentration of $5 \mu \mathrm{g} / \mathrm{mL}$.

A standard solution was prepared by dissolving $20 \mathrm{mg}$ of omeprazole standard powder in $20 \mathrm{~mL}$ methanol (HPLC grade). The volume was completed to $100 \mathrm{~mL}$ with $0.1 \mathrm{~N} \mathrm{NaOH}$ and the solution filtered 
through a Millipore nylon filter $(0.45 \mu \mathrm{m} \times$ $25 \mathrm{~mm})$. The filtrate was kept in a refrigerator protected from light. Concentrations used for the calibration graph ranged from 0.125 to $15 \mu \mathrm{g} / \mathrm{mL}$.

\section{Content uniformity testing}

Ten capsules were assayed individually and the content was expressed as a percentage of the label claim. The mean and relative standard deviation (SD) were calculated and compared as directed by United States Pharmacopeia (USP) 28.

\section{Drug release testing}

The evaluation of the biopharmaceutical quality of omeprazole capsules, regarding its dissolution characteristics, is not specifically regulated in the commonest pharmacopeias (USP28 includes a general monograph for enteric-coated products). The in vitro release from the studied capsules was thus assessed using the official method and compared to a modified method.

\section{Standard USP method}

Drug-release studies were performed according to the USP 28 procedure for delayed-release (enteric-coated) articles. In each study, 6 capsules were tested using dissolution apparatus type 2 . Initially, the capsules were exposed to a simulated gastric fluid $(750 \mathrm{~mL} 0.1 \mathrm{~N} \mathrm{HCl}, \mathrm{pH} 1)$ maintained at $37 \pm 0.5^{\circ} \mathrm{C}$ and rotated at $100 \mathrm{rpm}$ for 2 hours. After withdrawal of a $2 \mathrm{~mL}$ sample, $250 \mathrm{~mL}$ of $0.2 \mathrm{M} \mathrm{Na}_{3} \mathrm{PO}_{4}$ solution equilibrated at $37^{\circ} \mathrm{C}$ were added to the acidic medium and the $\mathrm{pH}$ was adjusted to $6.8 \pm$ 0.5 . Two $\mathrm{mL}$ samples were withdrawn at 5 , $10,20,30$ and 45 minutes and transferred to tubes containing $1 \mathrm{~mL} 0.3 \mathrm{~N} \mathrm{NaOH}$. Samples were then filtered through a $0.45 \mu \mathrm{m}$ cellulose nitrate membrane filter and kept in a refrigerator protected from light pending analysis. The analysis followed the same HPLC procedure described above.

\section{Modified release method}

The $\mathrm{pH}$ of the release medium used in the initial acid stage of the standard USP method was changed from $\mathrm{pH} 1$ to $\mathrm{pH} 4 \pm$ 0.5 [9] by adding $\mathrm{Na}_{2} \mathrm{HPO}_{4}$. Three capsules per brand were tested.

\section{Stability testing}

All products were subjected to the accelerated stability testing conditions recommended by the International Conference on Harmonization (ICH) guideline [10]. Samples of omeprazole capsules in their original packages were stored in an incubator at temperature of $40 \pm 2{ }^{\circ} \mathrm{C}$ and relative humidity (RH) of $75 \pm 5 \%$. The capsules were monitored over the 3-month study period for changes in the appearance of the pellets, drug content and drug release using the official USP release test.

\section{Data analysis and statistics}

Interbrand variation was evaluated using the one-way analysis of variance (ANOVA) followed by the Dunnett multiple comparison post-test to compare each of the local brands with the innovator's. $P<0.05$ was considered significant.

\section{Results}

Among the 7 brands tested, only brand $\mathrm{C}$ failed to conform with the USP requirements for content and content uniformity; its initial assay value was $121.02 \%$ and its content uniformity ranged from $118.17 \%$ to $127.44 \%$.

Figure $1 \mathrm{~A}$ and $\mathrm{B}$ show the release profiles of the different brands of omeprazole capsules using the official method and the modified one respectively. Pre-exposure to $\mathrm{pH} 1$ (Figure 1A) did not result in drug release; this was only initiated by switching the release medium $\mathrm{pH}$ to 6.8 . Significant differences were observed in omeprazole 

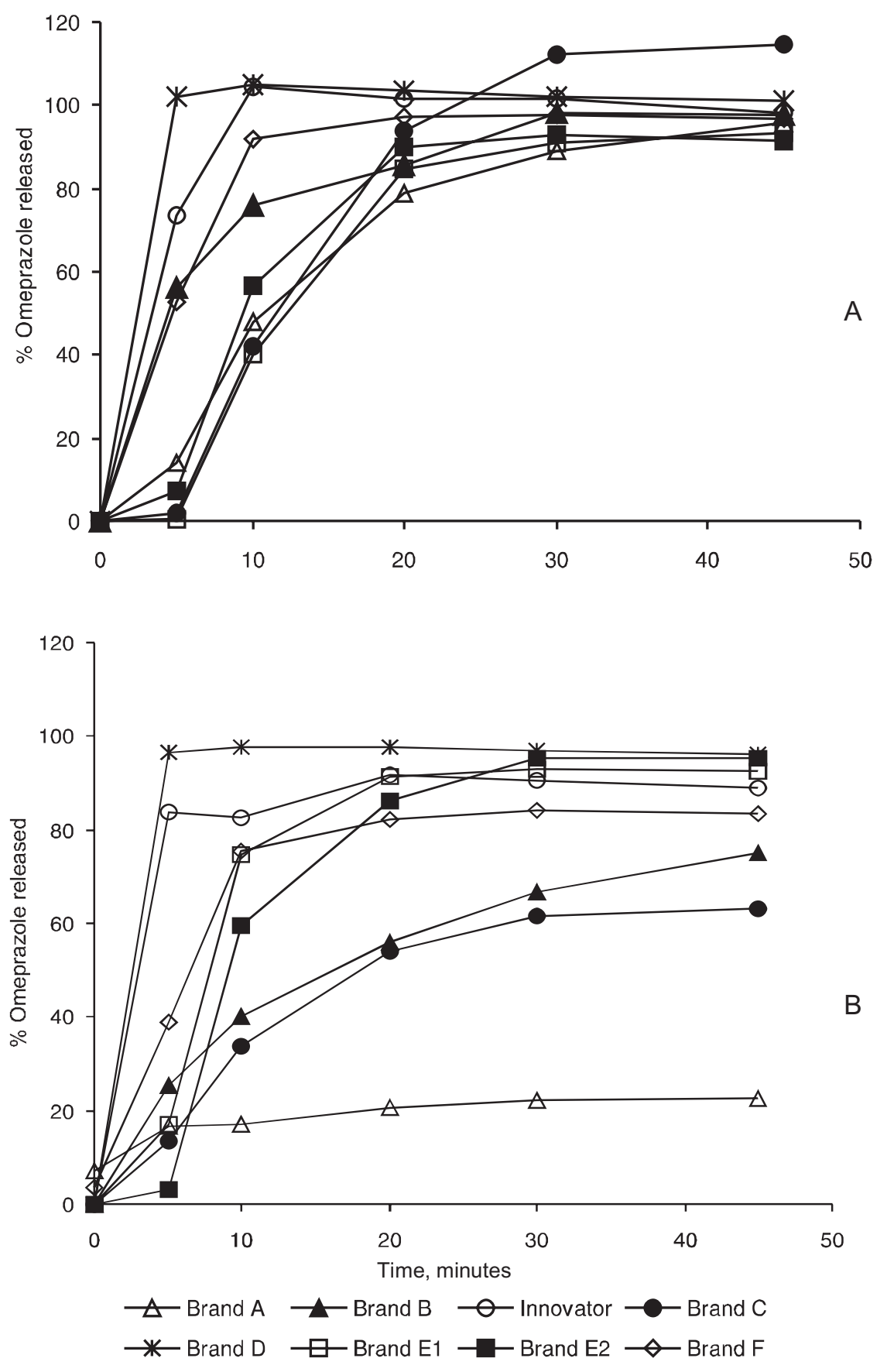

Figure 1 Release profiles of different brands of omeprazole capsules at pH 6.8 after preexposure to $\mathrm{pH} 1$ (A) or $\mathrm{pH} 4$ (B) for 2 hours 
release time between the innovator product and the tested brands for up to 10 minutes, except for brand $\mathrm{D}$ which had a release profile similar to that of the innovator. According to USP 28 , not less than $75 \%$ of the labeled omeprazole must be released, from a $20 \mathrm{mg}$ capsule, in 45 minutes; all tested brands exceeded $90 \%$ release (Figure 1A). It is worth noting that brand $\mathrm{C}$ achieved $120 \%$ release at 45 minutes, which is consistent with its higher drug content (121.02\%). Figure 1B shows obvious interbrand variations concerning both rate and extent of drug release after pre-exposure to $\mathrm{pH} 4$. In addition, brands $\mathrm{A}$ and $\mathrm{F}$ released $7.1 \%$ and $3.7 \%$ of their drug content at zero-time respectively. This may point to loss of coat integrity during the acidic stage ( $\mathrm{pH} 4)$.

Statistical evaluation of the release data indicated significant interbrand variability in the first 10 minutes of the release test, as well as significant differences between the innovator and each of brands A, B, C and E2. In addition, the innovator showed statistically significant differences regarding the extent of omeprazole release (\% released at 45 minutes) when compared to brands $\mathrm{A}, \mathrm{B}$ and $\mathrm{C}$.
Stability of the studied brands was monitored over a 3-month period at $40{ }^{\circ} \mathrm{C} / 75 \%$ $\mathrm{RH}$ using changes in pellet appearance, drug content and release stability as parameters (Table 2, Figure 2). At zero time, the majority of the observed pellets were white, except for brand B and D. Brand A and $\mathrm{F}$ showed progressive stickiness and darkening of the pellets (Table 2). The drug content of the tested brands was within the acceptable range $(90 \%-110 \%)$ at the end of 2 months storage, except for brand B which showed a drastic decrease to $1.79 \%$ (Figure 2A). After 3 months, 3 other brands, A, D and $\mathrm{F}$, in addition to brand $\mathrm{B}$, failed to maintain omeprazole content above $90 \%$. The initial omeprazole content of brand $\mathrm{C}$ was higher than the upper limit of the acceptable range (121.02\%); this decreased after 2 and 3 months storage to $103.6 \%$ and $102.33 \%$ respectively (Figure 2A).

Percentage drug release at 45 minutes over the 3 months storage is shown in Figure $2 \mathrm{~B}$. Brands $\mathrm{A}$ and $\mathrm{B}$ showed a significant decrease in omeprazole release at 45 minutes at 2 and 3 months; after 3 months omeprazole release at 45 minutes for brands $\mathrm{D}$ and $\mathrm{F}$ was also significantly lower.

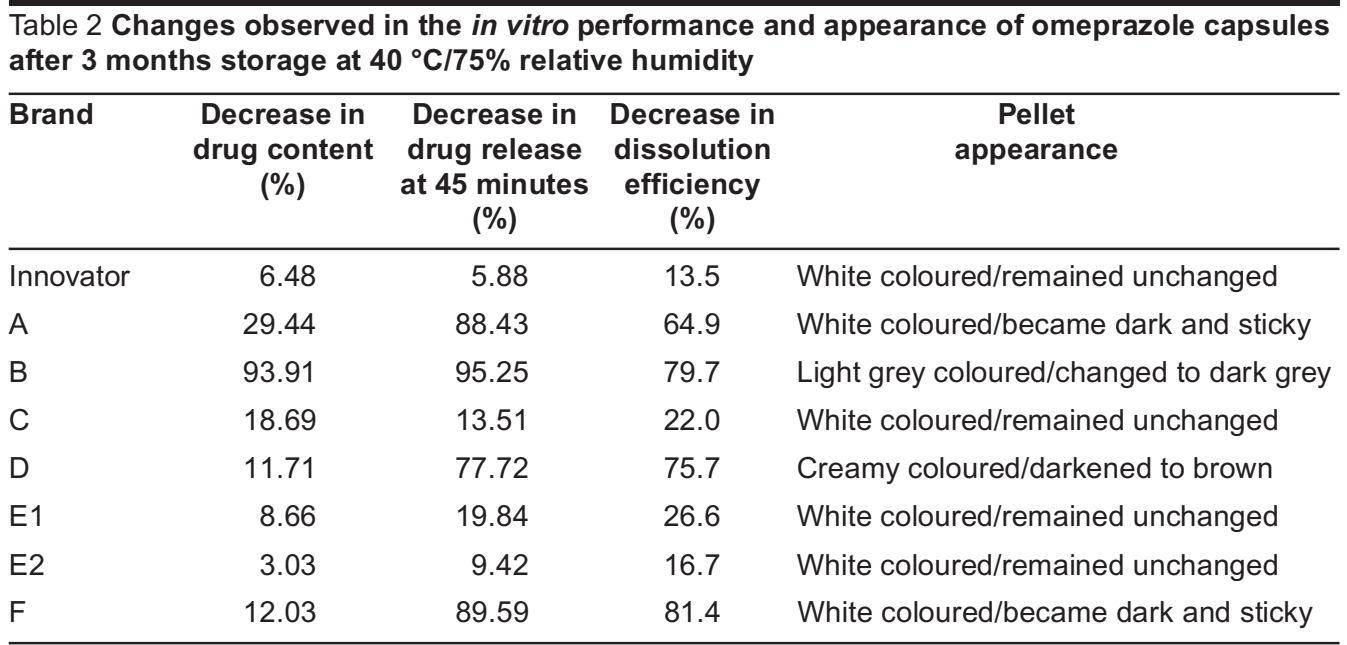



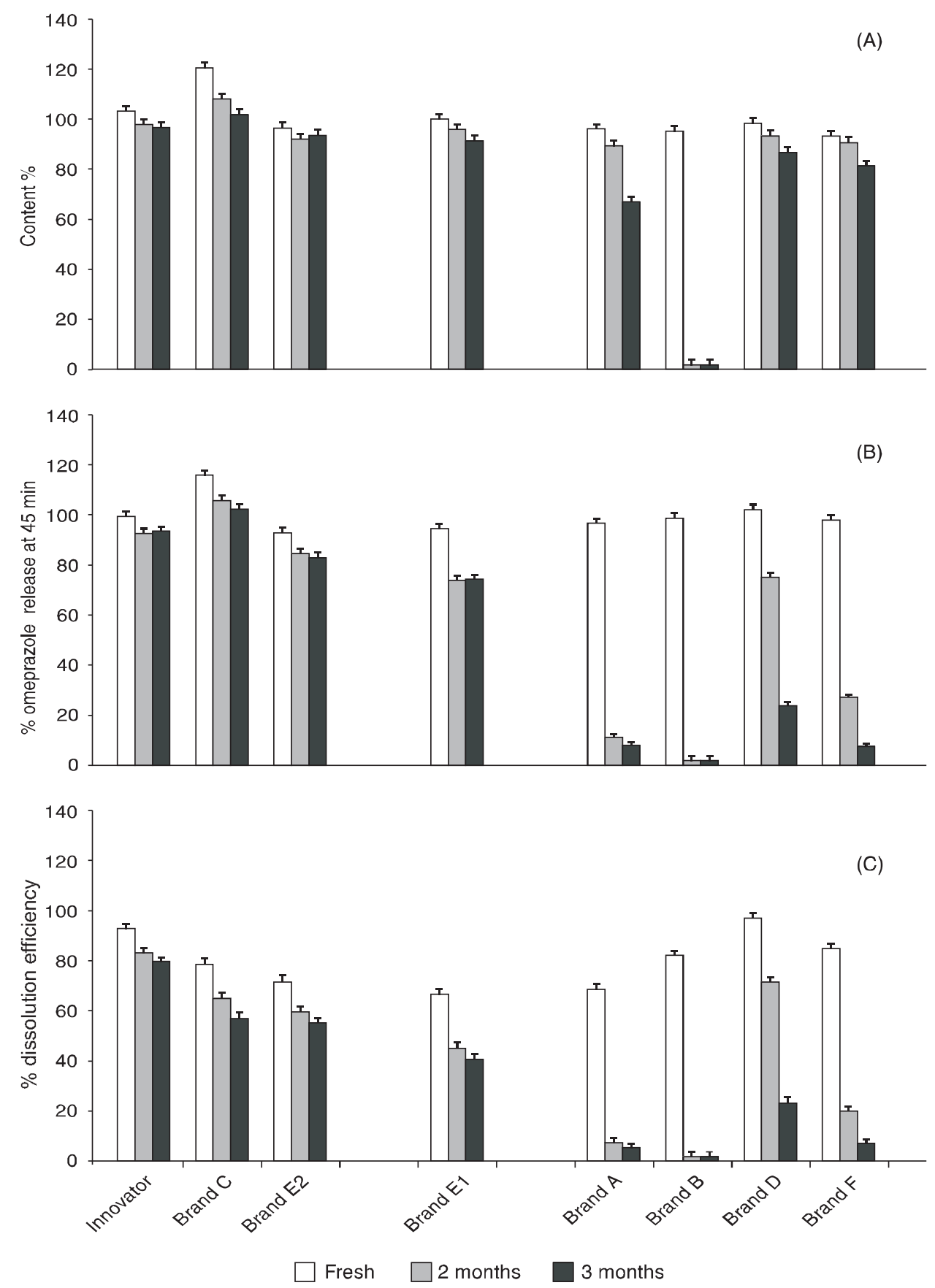

Figure 2 Changes in \% omeprazole content (A), \% release at 45 minutes (B) and \% dissolution efficiency (C) upon storage for 3 months at $40{ }^{\circ} \mathrm{C}$ and $75 \%$ relative humidity

المجلة الصحية لشرق المتوسط، منظمة الصحة العالمية، المجلد الثالث عشر، العدد ج، V... 


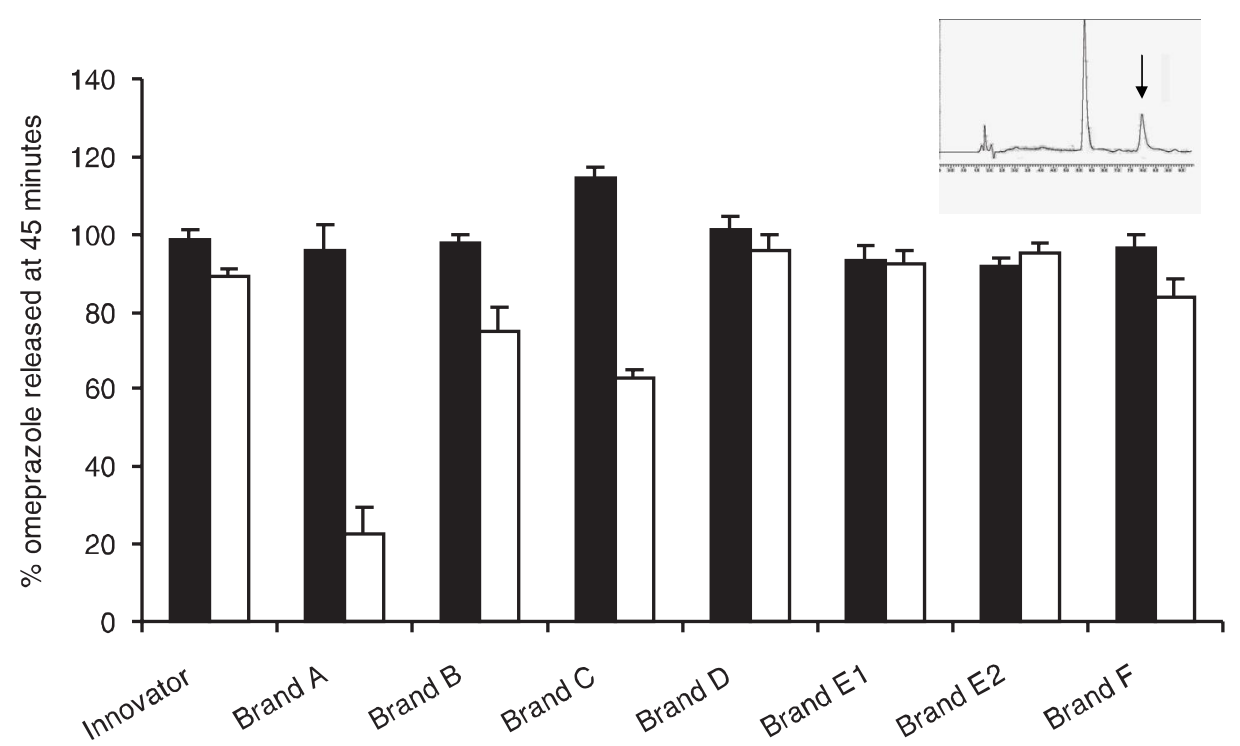

$\mathrm{pH} 1 \square \mathrm{pH} 4$

Figure 3 Influence of pre-exposure of omeprazole capsules to $\mathrm{pH} 1$ or $\mathrm{pH} 4$ on the \% omeprazole released at $\mathbf{4 5}$ minutes. The insert shows an extra peak in a chromatogram of a release sample at pH 4.

Release stability of omeprazole capsules upon storage was also studied using per cent dissolution efficiency (\% DE) (Figure 2C). Again, for brands $\mathrm{A}, \mathrm{B}, \mathrm{D}$ and $\mathrm{F}$, the $\% \mathrm{DE}$ decreased significantly at 3 months.

Regarding the influence of packaging materials on capsule stability (Tables 1 and 2), the results show the superiority of the innovator packaging. The PVC/PVdCaluminium blister of brand $\mathrm{B}$ proved to be the least protective. Amber glass bottles were the most protective of the locally used packaging materials.

Figure 3 shows the influence of preexposure of omeprazole capsules to $\mathrm{pH} 1$ or $\mathrm{pH} 4$ on the $\%$ omeprazole released at 45 minutes. There was a decrease in $\%$ released at 45 minutes for brands $\mathrm{A}, \mathrm{B}$ and $\mathrm{C}$ after pre-exposure to $\mathrm{pH} 4$ compared to $\mathrm{pH} 1$. The insert shows an extra peak in a chromatogram of a release sample at $\mathrm{pH} 4$.

\section{Discussion}

Inspection of the in vitro performance of omeprazole capsules produced by Egyptian companies revealed remarkable interbrand variations and significant differences between some of the local brands and the innovator.

Omeprazole, being a proton pump inhibitor (PPI), induces an increase in stomach $\mathrm{pH}$ up to 4 upon repeated administration [11]. Accordingly, performing the release test at this $\mathrm{pH}$ provides more realistic conditions for drug release from capsules [9]. The protective capacity of the enteric coat has been reported to be threatened at elevated gastric $\mathrm{pH}$ [12]. Our results showed a decrease in \% released at 45 minutes for brand $\mathrm{A}, \mathrm{B}$ and $\mathrm{C}$ after pre-exposure to $\mathrm{pH} 4$ compared to $\mathrm{pH}$ 1. This could be explained by the probable loss of gastric resistance of the enteric coat- 
ing polymers with consequent omeprazole degradation at $\mathrm{pH}$ 4. The appearance of a new peak, in addition to the omeprazole peak, in the release samples analysed confirmed this degradation.

Mathew et al. mentioned the appearance of 4 extra peaks when omeprazole was subjected to drastic acidic conditions [2]. One of the degradation products $(\mathrm{H}$ 238/85Astra) was identified by Storpiritis and Rodrigues [8]. In addition to its capability to evaluate the protective capacity of the coating, the modified release method is more discriminative and can reveal differences in pharmaceutical quality of different omeprazole capsule brands, which might be obscured under the conventional USP test. Elkoshi et al. showed that pre-exposure of omeprazole capsules to $\mathrm{pH} 3$ or 4 was more discriminative and resulted in release data that could correlate well with in vivo availability, while the official test results did not reflect the actual in vivo behaviour [12].

The stability of the tested capsule brands was monitored over 3 months of storage; the results revealed that the tested brands could be classified in 3 categories (Figure 2). The first one includes the innovator and brands $\mathrm{C}$ and E2, which showed drug content and $\%$ release at 45 minutes above the USP limits throughout the 3-month study period. The second category comprised brand E1, which maintained omeprazole content above $90 \%$ but failed to maintain drug release above $75 \%$. The observed decrease in drug release was not merely due to drug degradation, but rather may be attributed to changes in coating polymer properties [13]. The third category included products that suffered decrease in both omeprazole content $(<90 \%)$ and drug release $(<75 \%)$; this included brands A, B, D and F. These products showed a more pronounced decrease in release when compared to the decrease in content, indicating probable degradation during the acid stage of the dissolution test. The appearance of new peaks in the dissolution samples analysed of the 4 brands confirmed this degradation. The loss of the gastroresistance of enteric-coated formulae with ageing has been previously reported $[14,15]$. Moreover, the polymer structure may influence omeprazole stability [16]; the acid structure of the enteric coating polymers as well as the acidic by-products induced degradation of omeprazole.

The results revealed that colour change in pellets may be indicative of alteration in the coating polymer which in turn may influence drug release [8] and content stability [17]. Moreover, the influence of packaging materials on product stability was obvious when comparing brands E1 and E2; both were from the same source but with different packaging. The packaging material was most probably responsible for the differences in stability observed between the 2 brands.

Release stability of omeprazole capsules upon storage was further assessed using per cent dissolution efficiency ( $\%$ DE). The $\%$ decrease in DE after 3 months storage was statistically significant between the innovator and each of the tested brands except brand E2. This parameter is more realistic for comparison of release data as it takes into consideration all release data points rather than a single point [18].

\section{Conclusion}

Wide variations in the in vitro performance of omeprazole capsule products marketed in Egypt were observed and the modified release method proved to be more discriminative than the conventional USP one. The nature of the packaging materials had a clear influence on the performance of omeprazole capsules when stored: amber

المجلة الصحية لشرق المتو سط، منظمة الصحة العالمية، المجلد الثالث عشر، العدد ب، V... 
glass bottles ensured higher protection than blisters, strips or plastic bottles. The progressive darkening of the pellets indicated, qualitatively, the level of degradation of the product. The innovator was the brand most resistant to changes followed by brand E2. In addition, brand E2 is less expensive and thus could be considered more cost- effective for long-term therapy compared to the innovator.

The data obtained in this study strongly point to the need for assessment of the performance of drug products postmarketing and for strengthening the role of the national regulatory system to ensure the quality of multisource products.

\section{References}

1. Mostafavi SA, Tavakoli N. Relative bioavailability of omeprazole capsules after oral dosing. DARU, 2004, 12:146-50.

2. Mathew M, Gupta VD, Bailey RE. Stability of omeprazole solutions at various $\mathrm{pH}$ values as determined by high-performance liquid chromatography. Drug development and industrial pharmacy, 1995, 21:965-71.

3. Thoma K; Bechtold K. Influence of aqueous coatings on the stability of enteric coated pellets and tablets. European journal of pharmaceutics and biopharmaceutics, 1999, 47:39-50.

4. Ofner $\mathrm{CM}$ et al. Crosslinking studies in gelatin capsules treated with formaldehyde and in capsules exposed to elevated temperature and humidity. Journal of pharmaceutical sciences, 2001, 90:7988.

5. Chang RK, Raghavan KS, Hussain M.A. A study on gelatin capsule brittleness: moisture transfer between the capsule shell and its content. Journal of pharmaceutical sciences, 1998, 87:556-8.

6. Khali SAH, Barakat NS, Boraie NA. Effects of package type on the in vitro release and chemical stability of amoxicillin in capsules. Die Pharmazeutiche Industrie, 1991, 53:698-701.

7. Remak E et al. Cost-effectiveness comparison of current proton-pump inhibitors to treat gastro-oesophageal reflux dis- ease in the UK. Current medical research and opinion, 2005, 21:1505-17.

8. Storpiritis S, Rodrigues D. In vitro evaluation of dissolution properties and degradation products of omeprazole in entericcoated pellets. Drug development and industrial pharmacy, 1998, 24:1101-7.

9. Navarro MA et al. Differences in the release of omeprazole in 4 commercial preparations: influences of $\mathrm{pH}$ and ionic concentration. Gasteroenterology and hepatology, 1998, 21:63-70.

10. $Q 1 A(R 2):$ Stability testing of new drug substances and products. Geneva, $\mathrm{ICH}$, 2003.

11. Gouda BB et al. A comparison of the effects of ranitidine and omeprazole on volume and $\mathrm{pH}$ of gastric contents in elective surgical patients. European journal of anaesthesiology, 2004, 21:260-4.

12. Elkoshi $Z$ et al. Multiple dose studies can be a more sensitive assessment for bioequivalence than single-dose studies. The case with omeprazole. Clinical drug investigations, 2002, 22:585-92.

13. Petereit HU, Weisbord W. Formulation and process considerations affecting the stability of solid dosage forms formulated with methacrylate copolymers. European journal of pharmaceutics biopharmaceutics, 1999, 47:15-25.

14. Thoma K, Krautle T. Influence of pancreatin on the stability of gastroresistant 
coating. Part 3. Stability of gastroresistant pancreatin products under storage. Die Pharmzeutiche Industrie, 1999, 61:270-5.

15. Liu JP, Williams RO. Long-term stability of heat-humidity cured cellulose acetate phthalate coated beads. European journal of pharmaceutics and biopharmaceutics, 2002, 53:167-73.

16. Riedel A, Leopold CS. Degradation of omeprazole induced by enteric polymer solutions and aqueous dispersion: HPLC investigation. Drug development and industrial pharmacy, 2005, 31:151-60.

17. Palummo M et al. Stability of capsules containing omeprazole in enteric coated pellets. Bolletino chimico farmaceutico, 2000, 139:124-8.

18. Khan KA. The concept of dissolution efficiency. Journal of pharmacy and pharmacology, 1975, 27:48-9.

\section{Safety of children's medicines}

The lack of thorough and reliable clinical data on the way medicines affect children requires strengthened safety monitoring and vigilance of medicinal products. This is the fundamental message of Promoting safety of medicines for children.

Intended for policy-makers, manufacturers, medicines control bodies and researchers, the publication gives an overview of the problem and offers solutions on how best to address side effects from medicines in children. It is part of a broad effort WHO is initiating to expand children's access to quality-assured, safe and effective medicines.

For instance, countries should establish national and regional monitoring systems for the detection of serious adverse medicine reactions and medical errors in children; regulatory authorities need to make an effort to refine the science of clinical trials in children, create an active post-marketing surveillance programme and develop public databases of up-to-date information about efficacy and safety in paediatric medicines.

In addition, regulatory authorities need to make an effort to refine the science of clinical trials in children, create an active post-marketing surveillance programme and develop public databases of up to date information about efficacy and safety in paediatric medicines.

This publication can be ordered from the WHO bookshop (contact: bookorders@who.int) or can be downloaded as a PDF file at: http:// www.who.int/entity/medicines/publications/essentialmedicines/Promotion_safe_med_childrens.pdf.

المجلة الصحية لشرق المتو سط، منظمة الصحة العالمية، المجلد الثالث عشر، العدد Y، V... 